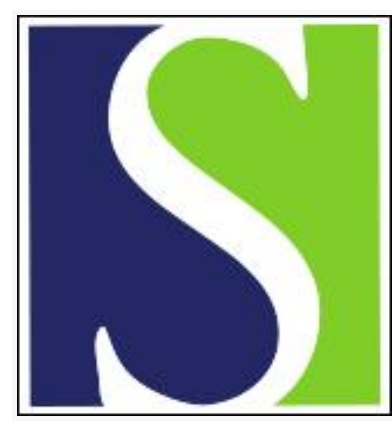

Scand J Work Environ Health 1996;22(3):223-226

https://doi.org/10.5271/sjweh.135

Issue date: Jun 1996

Exposure to styrene and mortality from nonmalignant diseases of the genitourinary system

by Welp E, Partanen T, Kogevinas M, Andersen A, Bellander T, Biocca M, Coggon D, Fontana V, Kolstad H, Lundberg I, Lynge E, Spence A, Ferro G, Boffetta P, Saracci R

Key terms: cohort study; nephritis; nephrosis; occupational health; solvent

This article in PubMed: www.ncbi.nlm.nih.gov/pubmed/8837269

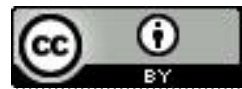




\title{
Exposure to styrene and mortality from nonmalignant diseases of the genitourinary system
}

\author{
by Esther Welp, MSc, ${ }^{1,2}$ Timo Partanen, PhD, ${ }^{1,3}$ Manolis Kogevinas, MD, ${ }^{1,4}$ Aage Andersen, MD, ${ }^{5}$ \\ Tom Bellander, PhD, ${ }^{6,7}$ Marco Biocca, MD, ${ }^{8}$ David Coggon, DM, ${ }^{9}$ Vincenzo Fontana, MSc, ${ }^{10}$ \\ Henrik Kolstad, MD, ${ }^{11}$ Ingvar Lundberg, MD, ${ }^{6}$ Elsebeth Lynge, PhD, ${ }^{12}$ Alan Spence, MSc, ${ }^{13}$ \\ Gilles Ferro, ${ }^{1}$ Paolo Boffetta, MD, ${ }^{1}$ Rodolfo Saracci, MD ${ }^{1,14}$
}

\begin{abstract}
Welp E, Partanen T, Kogevinas M, Andersen A, Bellander T, Biocca M, Coggon D, Fontana V, Kolstad H, Lundberg I, Lynge E, Spence A, Ferro G, Boffetta $P$, Saracci R. Exposure to styrene and mortality from nonmalignant diseases of the genitourinary system. Scand J Work Environ Health 1996;22:223-6.

Objective A historical cohort study was carried out to investigate mortality from nonmalignant diseases of the genitourinary system among workers in the reinforced plastics industry, where high workroom concentrations of styrene are encountered.

Methods The external comparisons in this report were based on an average of 12.6 years of retrospective follow-up of 35443 workers who were first employed in the reinforced plastics industry during 1945-1991 and were known to have been exposed to styrene in their work. For the internal comparisons, 2641 subjects with incomplete occupational histories were excluded, leaving 32802 subjects. Previous individual exposure histories to styrene were reconstructed through job histories and environmental and biological monitoring data.

Results Mortality from nonmalignant diseases of the genitourinary system $(\mathrm{N}=20)$ was associated with average exposure to styrene ( $\mathrm{P}$ for trend 0.05 ). Weaker increasing trends in risk were seen for time since first exposure and cumulative exposure, while no increase was identified for duration of exposure. There was a significant increasing trend in mortality from nephritis and nephrosis $(\mathrm{N}=5)$, associated with an increasing average level of exposure to styrene (P for trend 0.03 ). No clear trend was observed for time since first exposure, duration of exposure, or cumulative exposure.

Conclusions In this large cohort study of workers exposed to styrene, mortality from nonmalignant diseases of the genitourinary system increased as the average intensity of exposure increased. This finding indicates that other data should be scrutinized.
\end{abstract}

Key terms cohort study, nephritis, nephrosis, occupational health, solvent.

Styrene has extensive applications in the production of plastics and resins. Toxicologic studies on rats suggest that both the liver and kidney are susceptible to damage caused by repeated exposure to styrene (1). Nephrotoxic

1 Unit of Environmental Cancer Epidemiology, International Agency for Research on Cancer, Lyon, France.

2 Department of Environmental Health, University of Washington, Seattle, Washington, United States.

3 Finnish Institute of Occupational Health, Helsinki, Finland.

4 Department of Epidemiology and Public Health, IMIM, Barcelona, Spain.

5 The Cancer Registry of Norway, Oslo, Norway.

6 Department of Occupational Health, Karolinska Hospital, Stockholm, Sweden.

7 Center for Study and Prevention of Cancer, Florence, Italy.

8 Presidio Multizonale di Prevenzione, SEDI, Bologna, Italy.

9 Environmental Epidemiology Unit Medical Research Council, University of Southampton, Southampton, United Kingdom.

10 National Cancer Institute, Genoa, Italy.

11 Institute of Epidemiology and Social Medicine, University of Aarhus, Denmark.

12 Danish Cancer Society, Copenhagen, Denmark.

13 Health and Safety Executive, Bootle, United Kingdom.

14 Institute of Clinical Physiology, National Research Council, Pisa, Italy.

Reprint requests to: Dr P Boffetta, Unit of Environmental Cancer Epidemiology, International Agency for Research on Cancer, 150 Cours Albert-Thomas, 69372 Lyon, Cedex 08, France. e-mail: BOFFETTA@IARC.FR 
activity such as the induction of cellular dysfunction (2) and tubular injury (3) has been demonstrated in animal experiments. The evidence for renal effects in humans from chronic low-level exposure to styrene is inconsistent (4). Recent community-based case-referent studies have associated nephropathy with exposure to styrene (5) and other solvents $(6-8)$, but in the only published cohort study (9) the standardized mortality ratio (SMR) for glomerulonephritis did not deviate from 1.

This paper evaluates mortality from nonmalignant diseases of the genitourinary system in relation to exposure to styrene in a large international cohort study of workers in the glass-reinforced plastics industry, where high workroom concentrations of styrene are encountered. The study was initiated for the assessment of cancer risk (10).

\section{Subjects and methods}

A cohort of 40688 subjects ever employed in 660 European facilities manufacturing glass-reinforced plastics products was identified through eight research centers in Denmark, Finland, Italy, Norway, Sweden and the United Kingdom. Details of cohort recruitment have previously been presented (10). We excluded those unexposed $(\mathrm{N}=4044)$ or with uncertain exposure to styrene $(\mathrm{N}=1201)$. A total of 35443 exposed subjects remained for external comparisons according to national reference rates. They accumulated 446784 person-years during an average of 12.6 years of follow-up. For internal comparisons, we excluded 2641 subjects with incomplete occupational histories, leaving 32802 subjects and 405975 person-years. Mortality follow-up began at first exposure to styrene (between 1945 and 1991), or on the first date for which complete payrolls were available in the plant, whichever was later.

A styrene exposure data base was constructed from personal, environmental, and biological measurements. An exposure matrix was constructed by country and calendar period on job title, types of product, and methods of production (10). Estimates of individual exposure were reconstructed by applying the matrix to personal occupational histories. The exposures decreased in all the countries from recorded levels of around $200 \mathrm{ppm}$ in the $1960 \mathrm{~s}$ to $20-40 \mathrm{ppm}$ in the late $1980 \mathrm{~s}$.

For external comparisons, standardized mortality ratios (SMR) and 95\% confidence intervals (95\% CI) were calculated using the program PERSON-YEARS (11). The World Health Organization mortality data bank provided national mortality rates by gender, age, and calendar period.

Poisson regression models were used for the internal comparisons of the exposed subjects. Relative risks (RR) and associated $95 \%$ CI values were estimated using the program GLIM (12). We examined mortality from all nonmalignant urinary diseases [International Classifica- tion of Diseases, ninth revision (ICD-9) 580-6291, from specific diseases of the urinary system, namely, nephritis and nephrosis (ICD-9 580-583), and from other diseases of the genitourinary system (ICD-9 590-599) in relation to measures of exposure to styrene. Country, gender, age (five levels), and calendar period (four levels) were included in all the models. Time since first exposure, duration of exposure, cumulative exposure (ppm-years), and average exposure (ppm) were analyzed as categorical variables, as described previously (10). Cut-off points for the categories of average and cumulative exposure were selected on the basis of the distribution in the whole study population.

\section{Results}

Mortality from all causes among exposed workers was slightly lower than expected from national rates (2196 observed deaths, SMR 96, 95\% CI 92-100). A small deficit was also noted for all nonmalignant diseases of the genitourinary system (20 deaths, SMR 94, 95\% CI $57-145)$. Reference mortality rates for more specific categories of this group of diseases were not uniformly available for all the periods and populations.

Of the 20 deaths, five were from nephritis and nephrosis, three were from renal failure, ten were from other diseases of the urinary system, one was from a disorder of the prostate, and one was from disorders of the ovary and fallopian tube. Mortality from all nonmalignant diseases of the genitourinary system increased as the average exposure to styrene increased ( $\mathrm{P}$ for trend 0.05 ). Weaker increasing trends were seen for time since first exposure and cumulative exposure, while no increase was identified for duration of exposure (table 1). Mortality from nephritis and nephrosis increased with an increasing average level of exposure $(0.03)$, while no stable trend was evident for time since first exposure, duration of exposure, or cumulative exposure (table 1). Mortality from other diseases of the genitourinary system was associated with an increasing average exposure to styrene (0.01), but, again, not with the other indicators of exposure. Adjustment of the average exposure for time since first exposure did not alter the results. The slightly increasing trend in risk of other diseases of the genitourinary system by time since first exposure $(0.34)$ was due to confounding by the rate ratio (RR) for average exposure adjusted for time since first exposure: RR 1.0 for $<10$ years, RR 0.5 for $10-19$ years, and RR 0.4 for $\geq 20$ years).

\section{Discussion}

The objective of this study was to investigate the possible relationship between styrene exposure and diseases of the urinary system. Because there was a lack of reference rates available, the wider group of diseases of the genitourinary system was analyzed. Most deaths, re- 
ferred, however, to diseases of the urinary system, and separate analyses on nephritis and nephrosis were conducted.

The organs of the urinary system have been shown to be one of the target systems for the biological effects of styrene and its major primary metabolite, styrene-7,8oxide. It is, however, unlikely that styrene exposure increases risks of all diseases of the genitourinary system, such as renal infections. The mortality from all nonmalignant diseases of the genitourinary system was slightly lower than expected (20 deaths, SMR 94) in the comparison with national rates. This finding may be due to the healthy worker effect. The healthy worker effect was not particularly strong in this cohort, however, and adjustment for time since first exposure in the internal comparisons in the model for average exposure did not affect the association with average exposure.

The steep positive gradient for average exposure and mortality from all nonmalignant diseases of the genitourinary system, and the less steep gradient for cumulative exposure, are in agreement with the results of previous human studies $(8,13-14)$, which associated exposure to high levels of organic solvents with the occurrence of acute tubular necrosis, progressive glomerulonephritis, and chronic glomerulonephritis. Much of the evidence from epidemiologic studies is limited, however, by problems in the diagnoses and uncertainties about the quality and intensity of the solvent exposure. Solvents, hydrocarbon derivatives, and mixtures have on occasion been associated with the risk of renal cancer. In this study mortality from this cancer was lower than expected, however (SMR 77, 95\% CI 44-125) (10).

Of the 20 deaths from diseases of the genitourinary system in the internal comparisons in this study, eight were due to nephrosis and nephritis or renal failure. This proportion is about what would be expected from national mortality statistics. Nephritis and nephrosis are of special interest, considering recent case-referent studies associating these diseases with exposure to solvents (7, 14). Although the numbers were small, there was a significant increase in mortality from these diseases with an increasing average level of exposure to styrene. For mortality from other diseases of the urinary system, a similar increase with average exposure was observed. These findings suggest that very high exposures, rather than prolonged low exposures, cause severe damage in the renal system. This finding is in accordance with those of studies (15-16) associating acute tubular necrosis with high levels of exposure to organic solvents.

The results of this study are based on a small number of deaths, as can be seen from the width of the confidence intervals in table 1 . A concern is misclassification of exposure status, both qualitatively (inclusion in the cohort) and quantitatively. Such misclassification would not, however, be likely to produce spurious positive as-
Table 1. Mortality from diseases of the genitourinary system and exposure to styrene - internal comparisons (Poisson regression analysis). All relative risks (RR) were adjusted for country, age, calendar year, and gender. ( $95 \% \mathrm{Cl}=95 \%$ confidence interval)

\begin{tabular}{llll}
\hline Disease $^{\mathrm{a}}$ & $\begin{array}{c}\text { Number } \\
\text { of deaths }\end{array}$ & $\mathrm{RR}$ & $95 \% \mathrm{Cl}$ \\
\hline
\end{tabular}

All diseases of the genitourinary system $(580-629)$

Time since first exposure

$<10$ years

10 - 19 years

$9 \quad 1.00^{\mathrm{b}}$

$p$ for trend $=0.75$

Duration of exposure

$<1$ years

$1-3$ years
$4-9$ years

$\geq 10$ years

$\mathrm{p}$ for trend $=0.75$

Average exposure

$<60$ ppm

$60-119 \mathrm{ppm}$

$120-199 \mathrm{ppm}$

$\geq 200 \mathrm{ppm}$

p for trend $=0.05$

Cumulative exposure

$<10$ ppm-years

10-74 ppm-years

$75-199 \mathrm{ppm}-\mathrm{years}$

200-499 ppm-years

$\geq 500$ ppm-years

$.46 \quad 0.49-4.38$

$1.23 \quad 0.19-7.87$

phritis or nephrosis $(580-583)$

Time since first exposure

$<10$ years

$\geq 10$ years

Duration of exposure

$<1$ years

$\geq 1$ years

Average exposure

$<120 \mathrm{ppm}$

$120-199 \mathrm{ppm}$

$\geq 200 \mathrm{ppm}$

$p$ for trend $=0.03$

Cumulative exposure

$<10$ ppm-years

10-74 ppm-years

$75-199$ ppm-years

$\geq 200$ ppm-years
p for trend $=0.92$

$\begin{array}{lll}10 & 1.00^{\mathrm{b}} & . \\ 1 & 0.15 & 0.02-1.12 \\ 7 & 1.54 & 0.54-4.37\end{array}$

$\begin{array}{lll}7 & 1.54 & 0.54-4.37 \\ 2 & 0.94 & 0.18-4.90\end{array}$

ther diseases of the genitourinary system $(590-599)$

Time of exposure

$<10$ years

$10-19$ years

$\geq 20$ years

$p$ for trend $=0.34$

Duration of exposure

$<1$ years

$1-3$ years

4 -9 years

$\geq 10$ years

$p$ for trend $=0.65$

$\begin{array}{lll}2 & 1.00^{\mathrm{b}} & \\ 6 & 1.98 & 0.39-9.99 \\ 7 & 4.12 & 0.81-21 . \dagger \\ 5 & 4.53 & 0.78-26.2\end{array}$

Average exposure

$<60$ ppm

$60-119 \mathrm{ppm}$

120--199 ppm

$\geq 200 \mathrm{ppm}$

$p$ for trend $=0.01$

Cumulative exposure

$<75$ ppm-years

75-199 ppm-years

200-499 ppm-years

$\geq 500$ ppm-years

$p$ for trend $=0.25$
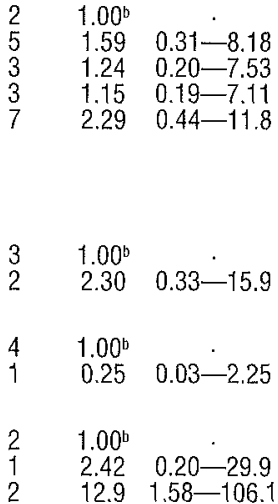

Code of the International Classification of Diseases, ninth revision, in parentheses.

b Reference category. 
sociations, such as the one found according to average styrene exposure. Exposure to other toxic agents is an additional source of concern in this study, in particular since a large part of the cohort was employed in the reinforced plastics industry for a relatively short period of time. No information is available on such possible confounders, which, however, should have been highly correlated with styrene exposure to cause the pattern by average and cumulative exposure seen in this study.

In conclusion, in this cohort study of workers exposed to styrene, mortality from nonmalignant diseases of the genitourinary system increased as the average intensity of exposure increased. However, due to limited statistical power and possible confounding the results should be interpreted with caution.

\section{Acknowledgments}

This study was partly supported by the European Commission, BIOMED-1 program (contract No BMH1CT92-1110). Ms E Welp was supported by a special training award from the International Agency for Research on Cancer. Dr M Kogevinas was partly supported by a fellowship from the Ministry of Education and Science, Spain (DGICT, SAB95-0189).

\section{References}

1. Withey JR, Collins PG. The distribution and pharmacokinetics of styrene monomer in rats by the pulmonary route. $\mathrm{J}$ Environ Pathol Toxicol 1979;2:1329_42.

2. Chakrabarti S, Vu DD, Cote MG. Effects of cysteine derivatives of styrene on the transport of p-aminohippurate ion in renal plasma membrane vesicles. Arch Toxicol 1991;65:36672 .

3. Bernard AM, de Russis R, Normand JC, Lauwerys RR. Evaluation of the subacute nephrotoxicity of cyclohexane and other industrial solvents in the female Sprague-Dawley rat. Toxicol Lett 1989:45:271-80.

4. Vyskocil A, Emminger S, Malir F, Fiala Z, Tusl M, Ettlerova E, et al. Lack of nephrotoxicity of styrene at current TLV level
(50 ppm). Int Arch Occup Environ Health 1989;61:409-11.

5. Tabacova S, Balabaeva L. Environmental pollutants in relation to complications of pregnancy. Environ Health Perspect 1993;101s2:27-31.

6. Mutti A, Alinovi R, Bergamaschi E, Biagini C, Cavazzini S, Franchini I, et al. Nephropathies and exposure to perchloroethylene in dry-cleaners. Lancet 1992;340:189-93.

7. Porro A, Lomonte C, Coratelli P, Passavanti G, Ferri GM, Assennato G. Chronic glomerulonephritis and exposure to solvents: a case-referent study. Br J Ind Med 1992;49:73842.

8. Stengel B, Cenee S, Limasset J-C, Protois J-C, Marcelli A, Brochard $\mathrm{P}$, et al. Organic solvent exposure may increase the risk of glomerular nephropathies with chronic renal failure. Int J Epidemiol 1995;24:427-34.

9. Kolstad HA, Juel K, Olsen J, Lynge E. Exposure to styrene and chronic health effects: mortality and incidence of solid cancers in the Danish reinforced plastics industry. Occup Environ Med 1995;52:320-7.

10. Kogevinas M, Ferro G, Andersen A, Bellander T, Biocca M, Coggon D, et al. Cancer mortality in a historical cohort study of workers exposed to styrene. Scand J Work Environ Health 1994;20:251-61.

11. Coleman MP, Hermon C, Douglas A, Peto J. Cohort study analysis with a Fortran computer program. Int $\mathbf{J}$ Epidemiol 1986;15:134-7.

12. Payne CD. The GLIM system: release 3.77. Oxford (United Kingdom): Numerical Algorithms Group, 1985.

13. Steenland NK, Thun MJ, Ferguson CW, Port FK. Occupational and other exposures associated with male end-stage renal disease: a case/control study. Am J Public Health 1990;80:153-7.

14. Yaqoob M, Stevenson A, Mason H, Bell GM. Hydrocarbon exposure and tubular damage: additional factors in the progression of renal failure in primary glomerulonephritis. Q J Med 1993;86:661-7.

15. Nelson NA, Robins TG, Port FK. Solvent nephrotoxicity in humans and experimental animals. Am J Nephrol 1990;10:10-20.

16. Roy AT, Brautbar N, Lee DBN. Hydrocarbons and renal failure. Nephron 1991;58:385—92.

Received for publication: 2 August 1995 